\title{
A Novel Photovoltaic Off-grid Inverter Based on Boost Converter
}

\author{
Ling $\mathrm{MaO}^{\mathrm{a}}$, Jing Chen ${ }^{\mathrm{b}}$, Yi Deng ${ }^{\mathrm{c}}$, Cong Wang ${ }^{\mathrm{d}}$ \\ School of Automation, Wuhan University of Technology, Wuhan, 430070, China \\ aemail: 1614790205@qq.com, bemail: jingchen680@163.com, 'email: 402345008@qq.com, \\ demail: 705106418@qq.com
}

Keywords: Photovoltaic; Off-grid Inverter; the boost converter; PWM

\begin{abstract}
Isolated DC/DC converters have the disadvantage of inefficiency, instability, magnetic bias and shoot-through problems, etc. They also influence the other electrical devices severely in the same power network. Therefore, a novel photovoltaic off-grid inverter based on the boost converter is designed in this paper. The following works have been done in the study: to design the circuit of the photovoltaic off-grid inverter, to design the parameters of the photovoltaic off-grid inverter, to simulate. The research of this paper has laid a theoretical foundation for the photovoltaic off-grid inverter in industrial applications.
\end{abstract}

\section{Introduction}

Solar energy is characterized by clean, non-polluting and renewable energy. It is one of the energy with scale popularization value [1]. Photovoltaic power system is one of the forms of solar energy utilization. With the development of the photovoltaic power system, the photovoltaic inverter has become a hot research issue [2] [3].

At present, isolated DC/DC converters are widely used in the design of the photovoltaic inverter, such as full-bridge circuit, half-bridge circuit, push-pull circuit and so on. The full-bridge circuit and half-bridge circuit have the disadvantage of shoot-through problems and a complicated driving circuit. The push-pull circuit has the disadvantage of magnetic bias. It may lead to the instability of the system.

The boost circuit is characterized by efficiency, reliability and a simple structure. The design of the inductor of the boost circuit is relatively easy [4] [5]. The input current is continuous. The electromagnetic interference of the power system is reduced. The driving circuit is not complicated.

Therefore, aiming at the above-mentioned questions, a photovoltaic off-grid inverter based on the boost converter is designed in this paper. The following works have been done in the study: to design the circuit of the photovoltaic off-grid inverter, to design the parameters of the photovoltaic off-grid inverter, to simulate.

\section{Circuit of Photovoltaic Off-grid Inverter}

The voltage is converted from $37 \mathrm{~V}$ DC to AC $50 \mathrm{~Hz} / 220 \mathrm{~V}$ by the off-grid inverter. According to the requirement of the converting voltage, a circuit of the photovoltaic off-grid inverter is designed. The circuit of the photovoltaic off-grid inverter is shown in Fig.1.

The photovoltaic off-grid inverter consists of PV module, boost circuit, full-bridge inverter, filter and controller. The controller is realized by PI algorithm and the PWM module. The working process is as follows:

1) 37V DC generated by the PV module is boosted to 400V DC by the boost circuit.

2) $400 \mathrm{~V}$ DC is inverted into AC $50 \mathrm{~Hz} / 220 \mathrm{~V}$ by the full-bridge inverter.

3) The harmonic is filtered out by the filter.

PI algorithm is used in the closed-loop control. Trigger signals of the full-bridge inverter are provided by the PWM module. 


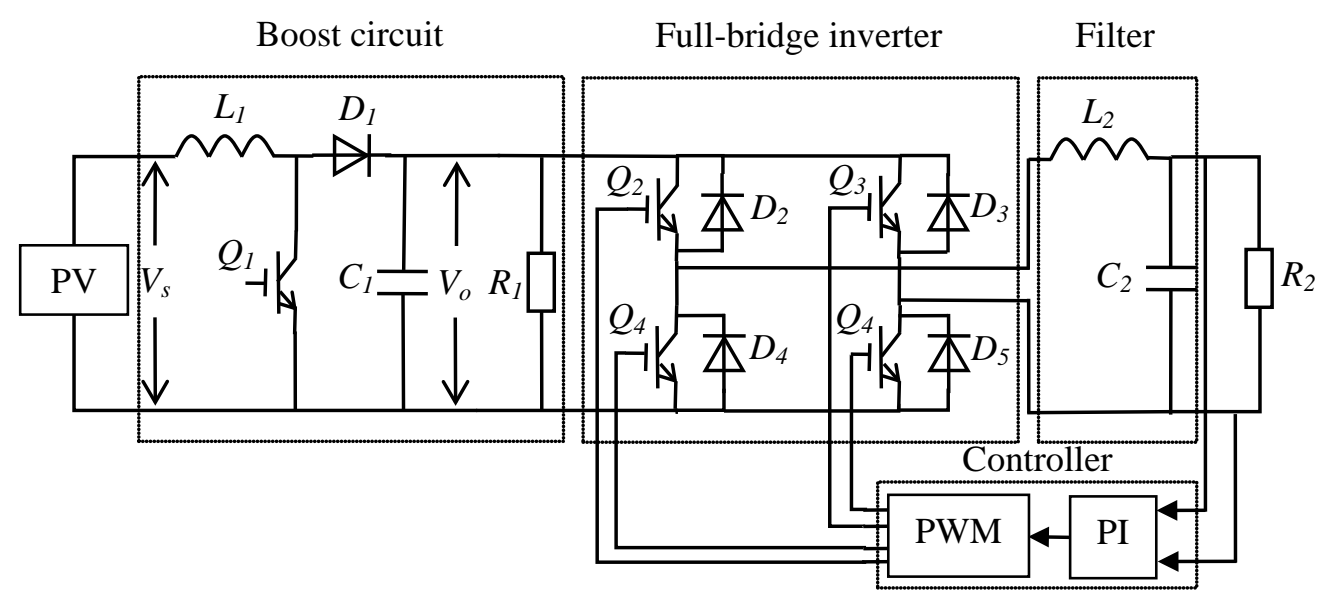

Fig.1. Circuit of the photovoltaic off-grid inverter

In the boost circuit, the inductance $L_{1}$ can store energy and limit the ripple current. The capacitance $C_{1}$ can decrease the output voltage ripple. In the filter, the inductance $L_{2}$ and the capacitance $C_{2}$ can filter harmonics. It is a kind of the band-pass filter. Therefore, the design of $L_{1}$, $C_{1}, L_{2}$ and $C_{2}$ is very important for the photovoltaic off-grid inverter.

\section{Parameters Design of Photovoltaic Off-grid Inverter}

Selecting the inductance $L_{1}$. In the continuous conduction mode, the duty cycle $D$, the input voltage $V_{S}$ and the output voltage $V_{0}$ must be satisfied the following formula:

$D=1-\frac{V_{S}}{V_{O}}$

$V_{O}, D$, the critical load current $I_{O B}$, the theoretical inductance $L_{1}{ }^{\prime}$ and the switching frequency $f_{s}$ must be satisfied the following formula:

$I_{O B}=\frac{V_{O}}{2 L_{1}^{\prime} f_{s}} D(1-D)^{2}$

$V_{O}, D$, the minimum load current $I_{O m i n}, L_{1}{ }^{\prime}$ and $f_{s}$ must be satisfied the following formula:

$I_{\text {Omin }}>\frac{V_{O}}{2 L_{1}^{\prime} f_{s}} D(1-D)^{2}$

The theoretical inductance $L_{1}{ }^{\prime}$ can be calculated by Eq.1 and Eq.3.

Selecting the capacitance $C_{1} . D, f_{s}$, the resistance $R_{1}$, the theoretical capacitance $C_{1}{ }^{\prime}$ and the output voltage ripple $\Delta V_{O} / V_{O}$ must be satisfied the following formula:

$\frac{\Delta V_{O}}{V_{O}}=D \cdot \frac{f_{c}}{f_{s}}=D \cdot \frac{1}{f_{s}} \cdot \frac{1}{R_{1} C_{1}^{\prime}}$

The theoretical capacitance $C 1^{\prime}$ can be calculated by Eq.4. In a practical application, a larger capacitance is needed to decrease the output voltage ripple.

Selecting the inductance $\boldsymbol{L}_{2}$ and the capacitance $\boldsymbol{C}_{2}$. The output voltage frequency $f$, the inductance $L_{2}$ and the capacitance $C_{2}$ must be satisfied the following formula:

$$
f=\frac{1}{2 \pi \sqrt{L_{2} C_{2}}}
$$

The inductance $L_{2}$ and the capacitance $C_{2}$ can be calculated by Eq.5. 


\section{Simulation of Photovoltaic Off-grid Inverter}

According to the circuit of the photovoltaic off-grid inverter, the model of the system is set up. The simulation model of a photovoltaic off-grid inverter is shown in Fig.2.

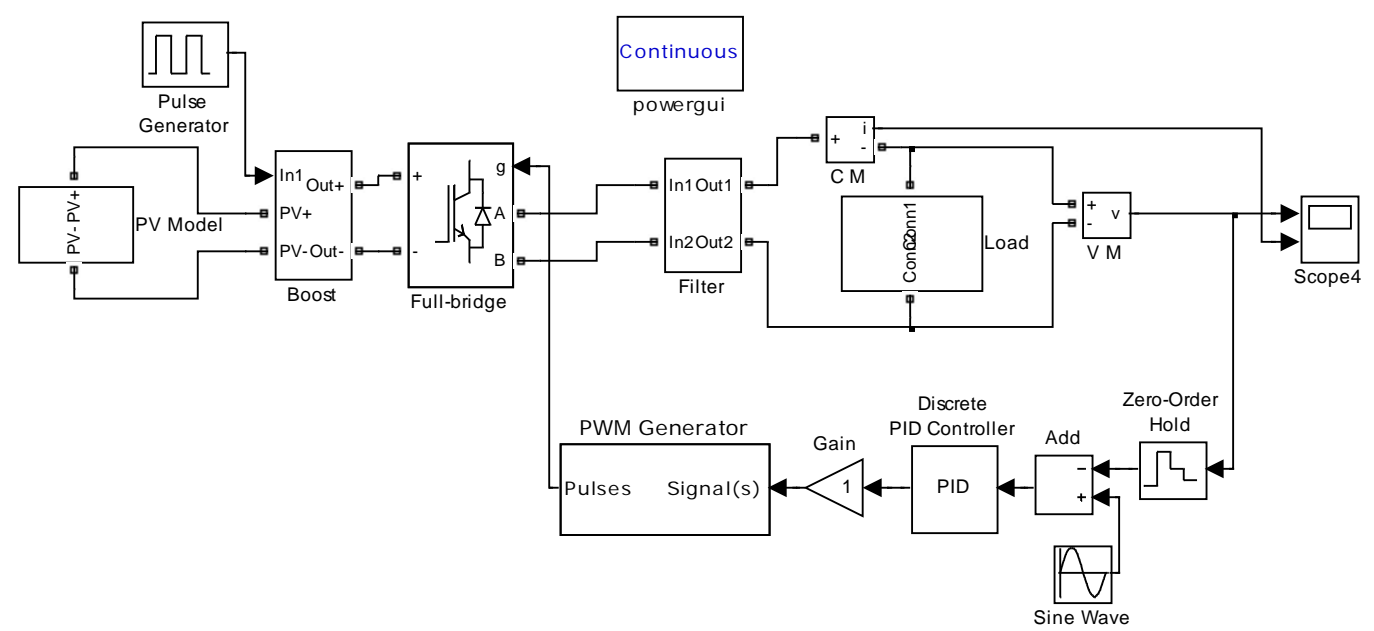

Fig.2. Simulation model of a photovoltaic off-grid inverter Simulation parameters are shown in Table 1.

Table 1. Simulation parameters

\begin{tabular}{c|c|c|c}
\hline Input voltage $V_{S}(\mathrm{~V})$ & 37 & Duty cycle $D$ & 0.91 \\
\hline Output voltage $V_{0}(\mathrm{~V})$ & 400 & Inductance $L_{1}(\mathrm{mH})$ & 0.1 \\
\hline Switching frequency $f_{s}(\mathrm{~Hz})$ & $15 \mathrm{k}$ & Capacitance $C_{1}(\mathrm{mF})$ & 5 \\
\hline The minimum load current $I_{\text {Omin }}(\mathrm{A})$ & 1 & Resistance $R_{1}(\Omega)$ & 2 \\
\hline Resistance $R_{1}(\Omega)$ & 2 & Inductance $L_{2}(\mathrm{mH})$ & 1.5 \\
\hline Output voltage ripple $\Delta V_{O} / V_{O}$ & $1 \%$ & Capacitance $C_{2}(\mu \mathrm{F})$ & 6761.6 \\
\hline Theoretical inductance $L_{1}{ }^{\prime}(\mathrm{mH})$ & 0.09828 & Resistance $R_{2}(\Omega)$ & 1.5 \\
\hline Theoretical capacitance $C 1^{\prime}(\mathrm{mF})$ & 3.03 & $\mathrm{Kp}$ & 0.175643 \\
\hline Systemic simulation time $(\mathrm{s})$ & 0.12 & $\mathrm{Ki}$ & 612.5 \\
\hline
\end{tabular}
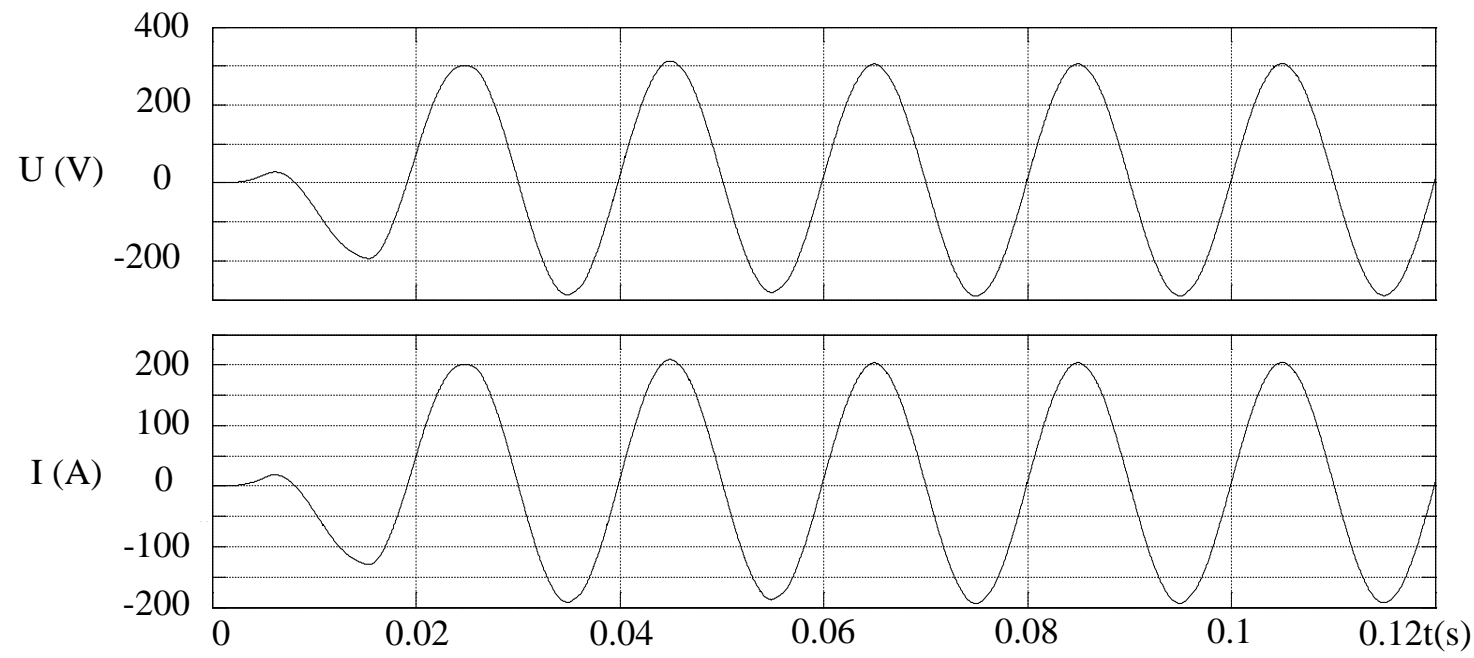

Simulation curves of the output voltage and current are shown in Fig. 3.

Fig.3. Simulation curves of the output voltage and current

In Fig.3, curves of the output voltage and current are sine wave. The frequency is $50 \mathrm{~Hz}$. The amplitude of the output voltage reaches expectations in the third cycle, and it keeps invariant. The phases of the voltage and the current are consistent. Therefore, the simulation model and parameters designing meet the design requirement of the photovoltaic inverter. 


\section{Conclusions}

Nowadays, isolated DC/DC converters are widely used in the design of the photovoltaic inverter. It has the disadvantage of inefficiency, instability, magnetic bias and shoot-through problems, etc. Therefore, a photovoltaic off-grid inverter based on the boost converter is designed in this paper.

The following works have been done in the study: to design the circuit of the photovoltaic off-grid inverter, to design the parameters of the photovoltaic off-grid inverter, to simulate. Simulation results show that the amplitude of the output voltage reaches expectations quickly, and it keeps invariant. The research of this paper has laid a theoretical foundation for the photovoltaic off-grid inverter in industrial applications.

\section{Acknowledgement}

This work was financially supported by the projects of Hubei Science and Technology Plans of China (Granted No: 2013BAA009).

\section{References}

[1] Weizeng Liu, Ming Zhao, Xu Yang, Tao Liu, Xinli Chang. Modeling and Analysis of the Influence of Photovoltaic Inverter on the Behavior of Photovoltaic Simulator in the Cascading Systems, International Power Electronics and Motion Control Conference. 2012.

[2] Xianwen Bao, Fang Zhuo, Yuan Tian, Peixuan Tan, Chang Xinli. Simplified Feedback Linearization Control of Three-Phase Photovoltaic Inverter with an LCL Filter [J], 2013.

[3] Wei Chen, Hui Shen, Youjun Deng, Jie Shu. Application and Development of the Inverter in the Photovoltaic System [J]. Power Electronics, 2006 (4) 130-133.

[4] Geoffrey R. Walker, Paul C. Sernia. Cascaded DC-DC Converter Connection of Photovoltaic Modules [J], 2004.

[5] Sajib Chakraborty, Saila Ishrat Annie, M. A. Razzak. Design of Single-Stage Buck and Boost Converters for Photovoltaic Inverter Applications, International Conference on Informatics, Electronics \& Vision (ICIEV). 2014. 